\title{
Designing Information Systems Courses in Flexible Learning Mode
}

\author{
Dr. Kay Bryant, \\ School of Management, Griffith University, Logan Campus \\ MEADOWBROOK. 4131 QLD. AUSTRALIA
}

\begin{abstract}
This paper reviews several frameworks for course design and develops one that incorporates the important elements of each for use in designing Information Systems courses. The development process revealed that there was a framework within a framework. The refined framework consists of two levels: the higher order cyclical framework and the lower level design/redesign framework. Research on the applicability of the framework for the design and redesign of Information Systems courses has been undertaken and the results suggest support for the effectiveness of the framework.
\end{abstract}

\section{1: Introduction}

Educational programmes required by today's student cohorts are diverse and specific to their needs. Further, the use of information technologies affects the teaching and learning process. To meet the challenge, Universities provide a range of programmes delivered in a flexible mode that encompass the use of Internet technologies. Yet, the eclectic mix of students makes the provision of education in a flexible framework complex. Flexibility is usually understood to mean offering students choices in the learning environment to better meet their individual needs. Students are offered choices in class times; course content; location; assessment; completion dates; types of communication needed; and assignments relevant to the student's workplace [2]. The shift to flexible learning from the traditional approach is challenging for course planners. The main concern is how to plan for the new teaching and learning environment and then to design a course that provides a requisite level of flexibility. This paper overviews some design frameworks and develops one that incorporates the relevant elements of each. The first section presents a comparison of design frameworks in order to identify important design issues that should be undertaken when designing a course in Information Systems (IS) that is to be offered in flexible mode. The next section describes the design framework at a macro level with a more detailed discussion provided in the third section, followed by the application of the framework to IS courses. The final section provides evidence on the application of the framework to three IS courses.

\section{2: Frameworks for Course Design}

Several design models/frameworks were reviewed for this study $[4,6,7]$. The frameworks share similar stages: objectives, learner characteristics, assessment, learning and teaching strategies, content and resources. Only two explicitly mention evaluation - an important stage in the design/development process. No explicit mention of reflection is made in any model. It may be implicit in the
Evaluation elements and in Gibbs' [4] Coherent and incoherent element. The framework evaluation revealed both the linear and cyclical models [7] were too structured and did not seem to have the flexibility to enable a return to a previous stage. The 2-stage interactive model [7] appears to be more flexible. The Method for flexible instructional module development [6] also has appeal. The 2-stage and Method models provide a pedagogical structure on which to base a framework for IS course design within a flexible delivery environment. In both cases, some preliminary activities are required. A set of characteristics is identified in the 2-stage interactive model while a generic module is designed under the Method approach. The relevant elements from the Method approach were integrated into the 2-stage interactive model. Yet combining these two models did not offer all the desired elements for flexible teaching/ learning environment, so these were added into the framework. This process became problematic as too many aspects were being incorporated into the framework. On reflection, the process revealed that there was a framework within a framework. The refined framework consists of two levels: the higher order cyclical level and the lower level design/redesign level; both of which are discussed in the next two sections.

\section{3: The Design Cycle}

At the macro level, the Course Design Cycle provides an overview of course design and implementation. The higher-order cyclical framework was based on Kolb's learning cycle $[5, \mathrm{p} 30]$. Kolb's model was adapted to suit a flexible approach by using the elements referred to as Design, Implementation, Reflection, Redesign. The design cycle is similar to Tyler's Curriculum Cycle [in 10, $\mathrm{p}$ 62] of analyse, design, implement and evaluate. The design cycle begins with the Design process, then it is implemented and the experience reflected upon. If, at this point, no changes are required, the Design cycle ends, though a more likely outcome of the reflection process would be recommendations for change. Revisions, that is redesign, are then undertaken while flagging their impact. Implementation of the redesign is done, followed by reflection activities. The cycle will then either end or continue with redesign based on further recommendations for change. If there are no revisions to be undertaken in the design/redesign of the course, a time line should be established whereby the review process should begin again at some point in the future, for example, within 12 months. By establishing the review date, course planners will then be able to reflect on the current design and determine whether any changes should be recommended. 


\section{4: A Framework for Course Design/Redesign}

The course design/redesign (D/R) framework provides a detailed view of the design and redesign elements of the design cycle. It is a generic framework that can be applied to and/or modified to suit IS courses requiring design or redesign. The framework is divided into two parts: the course and module levels as shown as Figure 1.

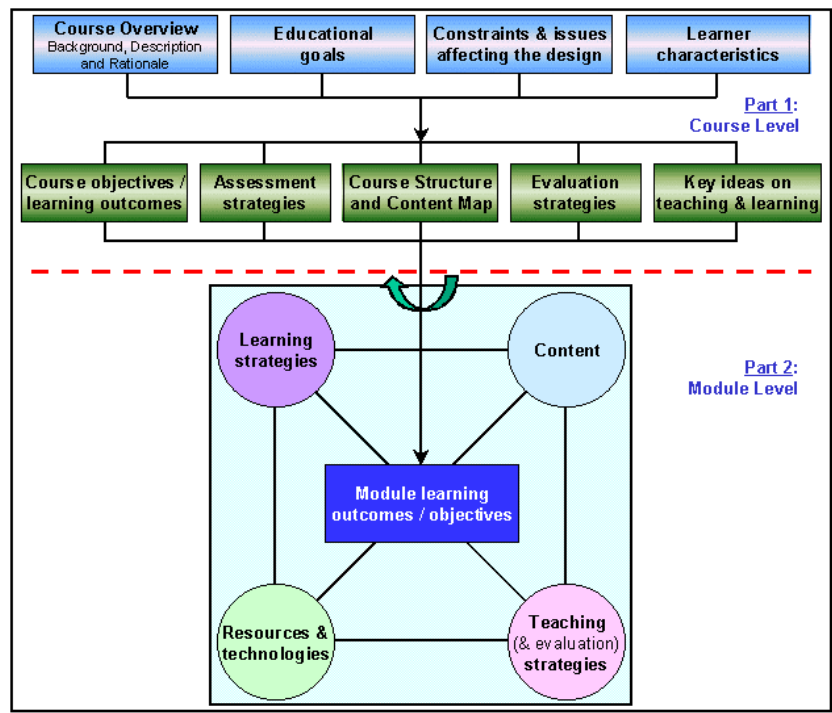

Figure 1: Course design/redesign framework

Print [7] regards the development and design as being essential elements in the curriculum development process. His discussion is focused around the various forms of curriculum design, which he categorises as:

- Subject-centred - teaching pivots around an established body of knowledge, ie content;

- Learner-centred - the course design ensues from the needs, interests and purposes of the student individual development is stressed;

- Problem-centred - learner attention is fixed on problems and their resolution; and

- Core designs - a common set of skills and knowledge that all learners should possess.

The second and third models have most appeal for IS courses. Learner-centred designs are not as pre-planned as problem-based designs as they usually evolve from teacher-student interactions. Problem-centred designs focus more on the group and group activities. Still, designers can have purposeful intentions with respect to student learning and still incorporate group activities that are centred on problem-based learning. Student development and learning are paramount in both designs.

The course level itself consists of two distinct sets of activities. Preliminary activities (depicted in the top row of Figure 1) are required prior to the specific course level components (shown in the second row) being undertaken. Once the course level components have been explored, the design process proceeds to the module level. At the module level, the design activities shown below the dotted line in Figure 1 are repeated for each module within the course. While the learning objectives and/or outcomes are the usual starting point for design activities, there is no sequential flow between the other components. It is an interactive process where changes in one aspect can and often will cause a change in one or more of the remaining components. The next section describes the application of the framework to IS courses.

\section{5: Application to IS Courses}

Three courses were redesigned using the $\mathrm{D} / \mathrm{R}$ framework; two were second year courses and the other was a third year course. While the design process was the same for each of the course, the course content and assessment strategies were different. Once the planning team was assembled, the redesign process began.

\section{1: Part 1: Course level design}

The course level consists of two sets of activities: preliminary and specific. Preliminary activities include providing a course overview; devising the educational objectives; identifying any constraints and issues that may affect the design; and learner characteristics. The more specific course level activities are determining course objectives/ learning outcomes; assessment strategies; course structure and content; course evaluation strategies and key ideas about teaching and learning. Preliminary activities are discussed before the specific activities.

Course Overview: An overview of the courses was formulated by including a short description and any relevant background information. This included but was not be limited to the School offering the courses, the degree program and major to which the courses belonged, how the courses related to existing courses, and what prerequisites/co-requisites were necessary. A rational for the course was also devised. Some of the information about the course was drawn from official documents concerning the course proposal. Documentation of the course design begins at this point.

Educational Goals: By grounding the design of the courses in theory, the broad educational goals for the courses were identified. Accordingly, five educational objectives were devised to underpin these courses: 1) Provide a high-quality teaching and learning environment; 2) Provide a level of flexibility that will maximise the learning potential of the students; 3) Recognise who the students are and where their experience and interests lie and provide a student-centred approach; 4) Provide an online environment that not only includes course content, but also provides the students with opportunities to interact with the system to develop essential skills; and 5) Maximise face-to-face interactions between students and the teacher through the use of experiential learning rather than information dissemination. The learning outcomes and objectives for the courses and the web sites were established with these educational objectives in mind.

Constraints and Issues affecting the Design: The constraints and issues affecting the course design including the characteristics of the learning environment must be identified. A situational analysis [7] was conducted at School level to identify factors that are internal and external to a setting, that is a context.

- Learning Issues: Observations and evaluations provided by previous IS student cohorts revealed areas of concern. Students struggle in IS courses when they fail to recognise two main issues. They often do not understand, early in the course, how what they are learning will fit into their work place and they usually 
underestimate the time needed to apply the theory to actual cases. Using a content map, as well as assessment items that related to real-world problems and which were submitted progressively throughout the semester reduced the effects of these problems.

- Student Issues: Several obstacles were evident including: level of computer literacy and skill; the students' needs and learning styles; relevance of the content to the workplace; and insufficient time to engage in learning activities. Strategies were chosen to minimise them. Skill levels were managed by having a clear structure and logical flow of content and learning; learning activities related to real-life; a proper level of student support; and a web site that was easy to navigate and use. A mix of learning options was used to support different learning styles. The relevance of the content was influenced though assessment items that were actual business problems, teaching strategies that included seminars by industry experts, actual business cases and teaching examples. Lastly, the amount of content covered in the course was suitable to achieve the learning objectives.

- External Factors: External factors that had an impact on curriculum design included the requirements of professional organisations, industry and desires of employers. Other factors impacting the design were the Institutional and School contexts.

Learner Characteristics: The diversity in educational background, educational requirements, work experience, ages and cultural backgrounds of the student body added complexity to the redesign process. Rowntree's model of learner characteristics [8, p.45] was used in developing a profile of students studying IS courses. His model has six separate elements: demographics, motivation, learning factors, course setting, resource factors, and other factors.

Course Learning Objectives: Learning objectives/ outcomes is the first of the course specific components of the $\mathrm{D} / \mathrm{R}$ framework. The specific objectives/outcomes of the course were developed before any other element, as they are all dependent on the learning outcomes. The objectives were stated so the outcome could be measured. Further, they were sufficiently explicit to facilitate the design and implementation of teaching/ learning activities (TLAs) and suitable assessment strategies. The objectives underpinned the course design so the assessment strategies, course content, and teaching and learning strategies could be constructively aligned with them.

Assessment Strategies: All assessment strategies were aligned with the learning objectives. Assessment within IS courses address two separate types of learning. The first relates to the understanding and application of the discipline concepts, while the other relates to knowledge of software tools and their skill in using them. Personal experience in teaching IS courses has shown that students have a better grasp of the content if assessment items are constructively aligned to the learning objectives and if they are submitted continuously during the semester. The assessment types best suited to IS courses include case studies, projects and problems. Summative assessment was the main focus for testing student learning. Formative assessment provided feedback to the students and teaching team. The projects were actual business problems requiring students to apply the theoretical constructs and skills they had learned to produce a solution. Students could choose a business and/or technology. These activities provided another level of complexity to the learning approach, and engendering the development of the higher-order processing skills. Further, by submitting the project in two parts, students could gain feedback on their solution and incorporate it into their next submission.

Course Structure and Content Map: Course structure and content were constructively aligned with the learning objectives [1]. Wiles [10] explains curriculum structures ranging from highly structured to flexible and integrated designs. Within the IS discipline, variations of his simple content chains are often used. While content is presented sequentially, teaching and learning strategies need not be. Problem-based learning was used extensively and by basing the theory in real world problems, students could increase their learning and motivation. A concept map was used to help students understand how course elements were related to each other and to the assessment items.

Evaluation Strategies: A compelling argument for evaluating a course is that change is a desired process in learning and, hence, evaluation is the best way to improve that change process. Evaluation of the IS courses were planned at the outset and conducted during the course. Its primary purpose was to allow the teaching team to determine how well the students were learning and how the learning process could be improved. Formative evaluation of the learning process determined if the adjustments were functional and useful to the students and whether the improvements were impacting on the learning process. Summative evaluation was undertaken to determine if the improvements were as intended.

Key Ideas on Teaching and Learning: The overall teaching and learning strategies were identified - the principal issues being: Maintaining student interest and motivation; Learning activities that encourage a deeper level of learning so students are able to make the links from their study to their workplace; Structured learning program so students could work on their own if they so desired, as well as seeing the relationship between learning outcomes, content and assessment; and Maintaining the currency of the course content. The TLAs are identified in the next section. Once key ideas were accepted, all course level activities were completed and the design process proceeded to the next level.

\section{2: Part 2: Module level design}

The design activities in this stage are at the module level and are repeated for each module within the course. Activities include developing learning objectives, content, teaching strategies, learning activities and identifying the resources and technologies to support the teaching and learning strategies. While the learning objectives/ outcomes usually start the process, it is an interactive process where changes in one aspect often cause a change in any of the other components.

Module Learning Outcomes/Objectives: As with the course level objectives, the module and topic level learning outcomes were formulated first. The modulelevel or specific learning objectives are precise statements of educational intent that relate to modules and topics of the courses and were based on the course objectives [1]. Learning objectives checklists were used to ensure all stated objectives were encompassed in the design.

Module Content: The course structure and the overall content was identified earlier in the design process. At 
this level, the content for each module and topic were devised. A concept map was used to ensure relevant details had been identified. It is important for the planning team to remember and ensure the content is aligned not only to the learning objectives of the topic/module, but also to the course learning objectives. Each of the courses used a conceptual framework that organises the knowledge and skills needed by the students into key modules, each having several topics.

Teaching Strategies: The teaching strategies were selected to enhance student learning, that is, a deeper and more reflective form of learning was desired. The planning team selected strategies to ensure they were aligned the learning objectives so the desired outcomes were achieved. Teaching strategies included the use of the Internet and face-to-face classes. A Web site was developed for each course to provide information and content to the students. A hierarchical structure was imposed over the Web site so course materials and resources could be accessed in no more than three mouse clicks thereby facilitating ease of navigation through the site. Lectures were used, but the focus was in providing appropriate examples of how the theory was applied in business rather than disseminating information. Smaller group sessions - workshops, were structured in a flexible format, with some activities being teacher directed while others were peer- and self-directed. As part of the teaching strategies, the evaluation strategies were also planned. These strategies were designed so that they carried out the dual purpose of teaching and evaluation.

Learning Strategies: The student learning activities that would achieve the desired outcomes were devised to enhance interactions between students and the teacher as well as between and among students in both face-to-face and electronic situations. As part of the learning strategies and to provide students with a sense of ownership and control, they were encouraged to form informal study groups. Students were able to discuss course material, exercises, events and assessment items with other group members. The workshops were run on a regular basis and, although attendance was optional, they facilitated the interaction of students with the teaching staff. Students were set exercises that could be completed in their own time and, if problems or questions were encountered, these were then handled most effectively during the workshop sessions. The more difficult concepts within the course were illustrated through interactive examples delivered via the Web site. The workshop exercises were structured to ensure appropriate coverage of the theoretical aspects of each topic in the first instance, and then the application of the theory to case examples in the second. The relationship between the workshop exercises and the group project, along with their timing, ensured students understood the theoretical concepts and how they were applied before submitting the project.

Resources and Technologies: The resources to support the teaching and learning strategies along with the media on which the resources would reside were identified. A mix of print-based and technology-based resources was used. Students were provided with a printed version of some of the study material available on the Web site. The provision of a hard copy of this material ensured those students who preferred not to use the technology a great deal were not disadvantaged. The study guide contained a course overview, general assessment details, keynote presentation schedule, workshop schedule and outline, as well as the weekly workshop activities for the semester. The Web site contained: course details; assessment details and relevant supporting documentation as well as notes on how each topic applied to the projects; study materials; review materials for each topic; learning resources; Frequently Asked Questions facility; a Forum and chat facility; and a Noticeboard. Students were able to access the Web site from outside the university so they could undertake learning activities at their own convenience.

\section{6: Student Perception of the Courses}

This section explains the method used to explore the effectiveness of the Design/Redesign Framework. In order to elicit student opinions on the effectiveness of the Web technology and the teaching and learning strategy devised through the use of the $D / R$ framework, a survey instrument was developed. Section A contained questions on personal characteristics, while Section B contained questions on their experience with computing technology and flexible learning and the various instruments employed to measure their perceptions. Section C contained three open-ended questions. The courses that were redesigned using the $\mathrm{D} / \mathrm{R}$ framework were at the second year level (2) and third year level (1). They have been labelled using course number and year offered, that is, C1Y2, C2Y2 and C1Y3 respectively.

\section{1: Subjects}

Student demographic details are provided in Table 1. Students were aware that they were participating in an experiment to assess their perceptions of the effectiveness of teaching and learning approach. Participation in the survey was entirely voluntary on their part.

\begin{tabular}{lllrrr}
\hline Variable & Category & & C1Y2 & C2Y2 & C1Y3 \\
\hline Gender & Female & $=$ & 8 & 9 & 8 \\
Age & Male & $=$ & 6 & 12 & 11 \\
Country of & 25 years & $=$ & 12 & 14 & 15 \\
$\underline{\text { Origin }}$ & 25 years + & $=$ & 2 & 7 & 5 \\
Years of work & Oustralia & $=$ & 10 & 16 & 15 \\
experience & Other & $=$ & 4 & 3 & 4 \\
& No response & $=$ & 0 & 2 & 0 \\
& 1 -2 year & $=$ & 5 & 4 & 3 \\
N & 3-5 years & $=$ & 5 & 4 & 0 \\
& >5 years & $=$ & 3 & 5 & 8 \\
\hline
\end{tabular}

Table 1: Demographic Details

\section{2: Survey instruments}

Two instruments were drawn from the literature. The "Microcomputer Playfulness Measure", describes "an individual's tendency to interact spontaneously, inventively and imaginatively" with a computer $[9, \mathrm{p}$. 201]. It has been demonstrated that microcomputer playfulness relates positively to learning. The instrument was selected as an alternative to learning style to try to circumvent the current debate on learning styles. Another instrument - end-user computing satisfaction [3] - depicts the user's satisfaction with the web technology. It can be argued that students are in effect end-users and as such, the instrument is an appropriate choice. Both instruments have been tested and validated in the literature. 


\section{3: Results}

This section reports the results of data analyses on students' perceptions. The questionnaire's Section B focused on student's experience with computing and flexible learning. All questions on the course were evaluated using a 7-point Likert-type scale. The scale range, means and standard deviations of Section $\mathrm{B}$ questions are shown in Table 2. Only three students over the three courses rated themselves as below average in computing skills; no student deemed himself or herself as a Wizard. Webster and Martocchio [9] consider that users with a high level of playfulness, that is a score greater than 33, are more motivated and are better able to react to new technologies. It would appear that the majority of students can be regarded as playful and therefore, more likely to explore and use the web site. A single question asked the student to indicate their feelings about using web technology for learning. Again, the majority of students reacted positively to using web technology for learning; only five students overall were hesitant about using the technology. Only six students regarded flexible delivery as being ineffective for presenting teaching and learning materials, however ten were dissatisfied with the approach. Only four students in the first course did not like to use computers for learning, whereas all other students did. All but four students were frequent and regular users of the Web sites. Questions 15 to 25 were summed to form the end-user computing satisfaction measure [3]. The highest possible score is 77 , the lowest is 7 and the cut-off is 44 points. All but six students - two from each course - were satisfied. It is interesting to note that of the ten students least satisfied on the single question only three had a corresponding low satisfaction score. Overall there appears to be a general upward trend in the students perceptions across all questions.

\section{7: In Conclusion}

This paper has devised a framework that is suitable for designing IS courses offered in a flexible learning mode. For the framework to be considered useful, its application for the design of new courses and the redesign of existing courses must be tested. To this end, the framework has been applied in redesigning three IS courses for delivery in flexible learning mode. The student's perception of flexible delivery employing Web technologies that resulted from the application of the design/redesign framework is positive. Students appear to be satisfied with the delivery method and their interaction with it. This contention is supported by the favourable responses to the open-ended questions in the questionnaires. This evidence suggests that the use of a cohesive teaching and learning approach, which incorporates a comprehensive Web site, is an appropriate strategy for providing an effective learning environment for students studying IS. Research is now being undertaken on the framework's application to the design of new IS courses. The course design framework developed in this paper could conceivably be of use in other teaching areas that require students to understand basic concepts in the first instance, and then apply these concepts to real world problems and applications could employ the design/redesign framework. However, further research would be required to determine the appropriateness of the framework.

\section{8: References}

[1] Biggs J. Teaching for Quality Learning at University, Buckingham: SRHE \& Open University Press, 1999.

[2] Collis, B. New Didactics for University Instruction: Why and How? Computers \& Education, 1998, 31(3), 373-393.

[3] Doll, WJ. \& Torkzadeh, G. Measure of End-User Computing Satisfaction. MIS Quarterly, 1988, 12(2), 259-274.

[4] Gibbs, G. Course Design Components and Issues. in Designing Courses, Milton Keynes: The Open University, 1999, 8-22.

[5] McGill, I. and Beaty, L. Action Learning, (2nd Ed), London: Kogan Page, 1995.

[6] Nikolova, I. and Collis, B. Flexible Learning and Design of Instruction. British Journal of Educational Technology, 1998, 29(1), 59-72.

[7] Print, M. Curriculum Development and Design, (2nd Ed), St Leonards: Allen and Unwin, 1993.

[8] Rowntree, D. Profile your learners, in Preparing materials for open, distance and flexible learning, London: Kogan Page, 1994, 41-48.

[9] Webster, J. \& Martocchio, JJ. Microcomputer Playfulness Development of a Measure with Workplace Implications. MIS Quarterly, 1992, 16(2), 201-226.

[10] Wiles, J. Curriculum Essentials: A Resource for Educators, Needham Heights, MA: Allyn and Bacon, 1999.

\begin{tabular}{|c|c|c|c|c|c|c|c|c|c|c|c|c|}
\hline \multirow{2}{*}{\begin{tabular}{|l|} 
Questions from Section B of \\
Questionnaire
\end{tabular}} & \multicolumn{3}{|c|}{ Scale range } & \multicolumn{3}{|c|}{ C1Y2 } & \multicolumn{3}{|c|}{$\mathrm{C} 2 \mathrm{Y} 2$} & \multicolumn{3}{|c|}{ C1Y3 } \\
\hline & 1 & 4 & 7 & Mean & SD & Range & Mean & SD & Range & Mean & SD & Range \\
\hline $\begin{array}{l}\text { Q7. Rate your computing skills? } \\
\text { O8. Microcomputer Playfulness Measure }\end{array}$ & Meagre & Average & Wizard & $\begin{array}{r}4.4 \\
33.5\end{array}$ & 0.9 & $\begin{array}{c}2-6 \\
18-42\end{array}$ & $\begin{array}{r}4.6 \\
336\end{array}$ & 0.8 & $\begin{array}{c}3-6 \\
16-45\end{array}$ & $\begin{array}{r}5.0 \\
350\end{array}$ & 0.6 & $\begin{array}{c}4-6 \\
24-47\end{array}$ \\
\hline Q11. How would you describe your feelings & Hesitant & Indifferent & Excited & 4.7 & 1.2 & $2-6$ & 5.7 & 1.1 & $3-7$ & 5.8 & 1.2 & $3-7$ \\
\hline $\begin{array}{l}\text { Q12. How would you rate the effectiveness of } \\
\text { flexible delivery for your learning? }\end{array}$ & $\begin{array}{l}\text { Not Very } \\
\text { effective }\end{array}$ & Neutral & $\begin{array}{c}\text { Very } \\
\text { effective }\end{array}$ & 3.6 & 1.4 & $1-5$ & 5.2 & 1.4 & $2-7$ & 5.3 & 1.0 & $3-7$ \\
\hline $\begin{array}{l}\text { Q13. How satisfied are you with flexible } \\
\text { delivery for presenting teaching and learning } \\
\text { materials? }\end{array}$ & $\begin{array}{c}\text { Very } \\
\text { dissatisfied }\end{array}$ & Neutral & $\begin{array}{c}\text { Very } \\
\text { satisfied }\end{array}$ & 3.7 & 1.5 & $1-6$ & 5.0 & 1.2 & $2-7$ & 5.3 & 1.1 & $3-7$ \\
\hline Q14. I like to use computers for learning. & Not at all & - & $\begin{array}{l}\text { To a very } \\
\text { great extent }\end{array}$ & 4.5 & 1.2 & $3-7$ & 5.6 & 1.1 & $4-7$ & 5.6 & 0.9 & $4-7$ \\
\hline $\begin{array}{l}\text { Q15-25. End-user Computing Satisfaction } \\
\text { Measure }\end{array}$ & Not at all & - & $\begin{array}{l}\text { To a very } \\
\text { great extent }\end{array}$ & 50.1 & 9.2 & $40-73$ & 57.2 & 9.5 & $41-77$ & 59.8 & 10.5 & $36-75$ \\
\hline Q33. My usage of web site was: & Infrequent & - & Frequent & 5.1 & 1.1 & $3-7$ & 5.6 & 1.1 & $3-7$ & 5.1 & 1.4 & $3-7$ \\
\hline Q34. My use of web site was: & Sporadic & - & Regular & 5.1 & 1.1 & $2-7$ & 5.1 & 1.2 & $2-7$ & 5.4 & 1.1 & $3-7$ \\
\hline
\end{tabular}

Table 2: Questionnaire Results 